\title{
Percepção da equipe técnica sobre as práticas corporais na redução de danos em dependentes químicos
}

Technical team perception on the corporal practices in reducing damage in chemical dependents

Percepción del equipo técnica sobre las prácticas corporativas en la reducción de daños en dependientes químicos

\author{
George Saliba Manske ${ }^{\mathrm{I}}$, Luiz Antonio Onishi ${ }^{\mathrm{II}}$
}

\begin{abstract}
Resumo
Esta pesquisa teve como objetivo compreender a percepção da equipe técnica de um Centro de Atenção Psicossocial (CAPS-ad) num município do sul do Brasil sobre as influências das práticas corporais na redução de danos nos dependentes químicos. Os dados foram coletados através de uma entrevista semiestruturada, sendo analisados sob a ótica da análise temática. Os resultados da pesquisa demonstram que a equipe técnica possui conhecimento sobre as práticas corporais e, mesmo não conhecendo todo o universo desta atividade, acredita que deveria fazer parte do rol de opções a serem ofertadas quando da estruturação dos Projetos Terapêuticos Singulares (PTS).
\end{abstract}

Palavras-chave: Usuários de drogas; Exercício; Redução do dano; Práticas corporais

\begin{abstract}
This research aimed to understand the technical team perception of a Psychosocial Care Center (CAPS-ad) in a city in South Brazil on the corporal practices influences in reducing damages in chemical dependents. The data were collected through a semi-structured interview, which was analyzed from the perspective of the thematic analysis. The results of the research demonstrate that the technical team has knowledge about the corporal practices and, even though it does not know the whole universe of this activity, the technical team believes that it should be part of the list of options to be offered when structuring the Singular Therapeutic Projects (PTS).
\end{abstract}

Keywords: Drug Users; Exercise; Harm reduction; Body practices

\footnotetext{
${ }^{\text {I } U n i v e r s i d a d e ~ d o ~ V a l e ~ d o ~ I t a j a i ́-~ U N I V A L I ~-~ I t a j a i ́, ~ S C, ~ B r a s i l . ~ E n d e r e c ̧ o: ~ R u a ~ G a s p a r, ~ 167 / 301 . ~ B a i r r o ~ S a ̃ o ~ J u d a s, ~ I t a j a i ́ ~-~ S C, ~ B r a s i l, ~ C E P ~-~ 88303-320 ~-~ e-~}$ mail: gsmanske@yahoo.com.br

II Universidade do Vale do Itajaí- UNIVALI - Itajaí, SC, Brasil. toninho.onishi@gmail.com
} 


\section{Resúmen}

Esta investigación tuvo como objetivo comprender la percepción del equipo técnico de un Centro de Atención Psicosocial (CAPS-ad) en un municipio del sur de Brasil sobre las influencias de las prácticas corporales en la reducción de daños en los dependientes químicos. Los datos fueron recolectados a través de una entrevista semiestructurada, siendo analizados bajo la óptica del análisis temático. Los resultados de la investigación demuestran que el equipo técnico tiene conocimiento sobre las prácticas corporales $\mathrm{y}$, aun no conociendo todo el universo de esta actividad, cree que debería formar parte del rol de opciones a ser ofrecidas en la estructuración de los Proyectos Terapéuticos Singulares (PTS).

Palavras clave: Consumidores de drogas; Ejercicio; Reducción del daño; Prácticas corporales

\section{Introdução}

Desde a antiguidade há relatos da utilização de substâncias psicoativas por parte do ser humano. Com o desenvolvimento tecnológico, novas substâncias e drogas sintéticas foram criadas e estão sendo utilizadas. Devido às mudanças de hábitos, costumes e valores nas sociedades ocorreu um incremento da utilização desses produtos gerando um fenômeno concebido como drogadição. A Organização Mundial de Saúde (OMS), ao tratar dos cuidados primários à saúde mental, indica que o fenômeno da drogadição (concebido como uso e dependência de substâncias psicoativas) e do consumo de álcool corresponde a uma parcela significativa que origina casos e situações de perturbação mental, estabelecendo relações diretas entre o bem-estar físico e mental por pessoas acometidas por distúrbios ocasionados pelo consumo abusivo de tais substâncias (OMS, 2009).

Ainda no debate proposto pela OMS com a intenção de nortear uma política de integração da saúde mental aos serviços primários em saúde, destaca-se que o uso de drogas e o alcoolismo são considerados como mazelas sociais que acometem pessoas de diversas nacionalidades, classes sociais, gêneros, etnias ou credos (OMS, 2009). Objetivando o controle e a diminuição desta drogadição o Relatório Final da III Conferência Nacional de Saúde Mental (BRASIL, 2001), confere aos CAPS o valor estratégico para a mudança do modelo de assistência, defende a construção de uma política de saúde mental para os usuários de Álcool, Crack e outras drogas, e estabelece o controle social como garantia do avanço da Reforma Psiquiátrica no país tendo como seu principal propósito a construção da autonomia e reinserção social dos usuários por meio do trabalho, lazer, exercícios dos direitos e deveres civis, fortalecimento dos laços familiares e comunitários, utilizando a estratégia de redução de danos como política norteadora para Atenção Integral a Saúde Mental e a Usuários de Álcool, Crack e outras drogas.

Nesse âmbito, a Coordenação Geral da Saúde Mental (CGSM) - DAPES/SAS/MS desenvolveu, a partir de 2001, uma série de documentos sobre a articulação entre a Saúde Mental e a Atenção Básica. As principais diretrizes para esta articulação são: Apoio matricial de saúde mental às equipes de ESF: aumento da capacidade resolutiva das equipes; Priorização da saúde mental na formação das equipes da atenção básica; Ações de acompanhamento e avaliação das ações de saúde mental na atenção básica. Uma das principais estratégias propostas é a criação de equipes de apoio matricial, cuja função consiste nas ações de supervisão, atendimento 
compartilhado e capacitação em serviço, realizado por uma equipe de Saúde Mental para equipes ou profissionais da Atenção Básica (BRASIL, 2011). Com o avanço dos projetos voltados para o cuidado de usuários de álcool, crack e outras drogas a Política Nacional de Saúde Mental, instituiu a Portaria no 336 (BRASIL, 2002), que estabelece como serão constituídos os Centros de Atenção Psicossocial (CAPS) considerando a lei n 10.216, de 06 de dezembro de 2001 - que dispõe sobre a regulamentação dos direitos da pessoa com transtornos mentais e sobre o modelo assistencial em saúde mental. (BRASIL, 2004).

Os CAPS são serviços públicos de saúde que visam, como parte de uma rede comunitária, à substituição dos hospitais psiquiátricos - antigos manicômios - e de seus métodos para cuidar de transtornos mentais. (BRASIL, 2004). De forma geral, a Lei assegura às pessoas que se beneficiam das ações e serviços do SUS o direito a um tratamento que respeite a sua cidadania e que, por isso, deve ser realizado de preferência em serviços comunitários, sem excluí-los, portanto do convívio na sociedade.

Em 2003 o Ministério da Saúde, adota as estratégias de redução de danos como política norteadora para Atenção Integral a Usuários de Álcool, Crack e Outras Drogas e da Política de Saúde Mental, deixando assim de ser uma estratégia de Saúde Pública exclusiva dos Programas DST/AIDS (PASSOS; SOUZA, 2001). De modo objetivo podemos afirmar que Redução de Danos são ações organizadas pelo poder público que buscam a redução do uso e do consumo de substâncias psicoativas em dependentes químicos, sem que com isso se retire totalmente seu consumo ou a oferta, primando pela escolha e liberdade individual (POLLO-ARAÚJO; MOREIRA, 2008).

Para Gimeno et al (1998 apud PIMENTEL et al., 2008) fatores singulares estimulam o envolvimento e a permanência de usuários em programas de redução de danos, incluindo a pressão do estado, empregadores, familiares, amigos, sua vontade própria e a motivação para mudar seu comportamento em relação a utilização do uso dessas substâncias psicoativas. Os fatores individuais que levam ao envolvimento e a retenção incluem a existência de pressão ao tratamento por parte do sistema criminal judiciário, serviços de proteção à criança, empregadores, motivação para mudar o comportamento de uso de drogas e o grau de apoio da família e amigos. Com essa complexidade de fatores, diversos programas terapêuticos podem auxiliar ao tratamento desses dependentes químicos, incluindo as práticas corporais (GIMENO et al., 1998 apud PIMENTEL et al., 2008).

Práticas e pesquisas atuais evidenciam a importância das práticas corporais para a promoção da saúde na atenção primária, evidenciando a necessidade de maiores aprofundamentos e continuidades das ações existentes (FRAGA; CARVALHO; GOMES, 2013; GOMES; FRAGA; CARVALHO, 2015; WACHS; ALMEIDA; BRANDÃO, 2016). Além do mais, no tocante à saúde mental, é possível indicar que a participação em várias formas de atividades relacionadas às práticas corporais está associada com uma saúde mental positiva e com a melhora da qualidade de vida (BARBANTI, 2006). Nesse ínterim, prática corporal pode ser concebida como

toda manifestação gestual, como os exercícios, os jogos e as danças, com significado cultural compartilhado em determinado contexto. Quando as práticas corporais estão relacionadas ao esforço ou ao gasto energético utilizamos o termo atividade física. Já o termo recreação refere-se à condução de atividades lúdicas destinadas, predominantemente, à diversão (PIMENTEL et al., 2008). 
Neste estudo estamos entendendo práticas corporais como ações e movimentos corporais carregados de expressões culturais diversas que são marcadas historicamente, imbuídas de sentidos e significados partilhados pelos sujeitos que as praticam e produzem, e que acabam por constituir-se enquanto conteúdo possível do trabalho do profissional e professor de educação física (MANSKE; BARCELOS, 2016), neste caso, num CAPS-ad.

Para a realização desta pesquisa foi escolhido o CAPS-ad da Cidade de Itajaí - SC, visto esta unidade já ter possuído em seu programa terapêutico um espaço destinado às práticas corporais. E, na delimitação do objetivo de pesquisa, procuramos compreender qual a percepção da equipe técnica sobre as influências das práticas corporais na redução de danos nos dependentes químicos do Centro de Atenção Psicossocial - Álcool, Crack e outras drogas - CAPS-ad de Itajaí - SC.

\section{Métodos}

Esta pesquisa possui abordagem qualitativa, com objetivos exploratórios, tendo como procedimento a pesquisa de campo. Foi realizada com a equipe técnica do Centro de Atenção Psicossocial - Álcool, Crack e outras drogas (CAPS-ad) de Itajaí-SC, sem limitação de faixa etária, gênero, função, ou tempo de serviço na referida unidade. A coleta de dados foi realizada através de uma ficha de identificação e uma entrevista semiestrutura, que de acordo com Rizzini et al (1999), é aplicada a partir de um pequeno número de perguntas, para facilitar a sistematização e codificação.

Esta pesquisa foi orientada pela resolução no 466/12/96 do CNS e o projeto foi cadastrado na Plataforma Brasil, sendo enviado a um Comitê de Ética em Pesquisa para apreciação tendo sido aprovado com o Parecer Consubstanciado $\mathrm{n}^{\mathrm{o}}$ 1.537.589. A pesquisa se desenvolveu da seguinte forma: foi realizada inicialmente uma reunião individual com cada participante para esclarecer os objetivos propostos e agendar data e horário para as entrevistas; no ato da entrevista foi entregue o "Termo de Consentimento Livre e Esclarecido", para fins de regulamentação de sua participação na pesquisa; com o consentimento dos participantes as entrevistas foram gravadas e posteriormente transcritas integralmente a fim de preservar a fidedignidade da informação a ser analisada.

No que tange às análises de dados, estes foram analisados sob a ótica da análise temática, na medida em que este tipo de análise "é uma das formas que melhor se adequou a investigações qualitativas" (BARDIN, 1979). A aplicação dessa técnica de análise neste estudo se constituiu por três etapas, a saber, pré-análise, exploração do material, e tratamento dos resultados obtidos e interpretação. A seguir, destacamos os principais eixos de análise.

\section{Resultados e discussão}


O Centro de Atenção Psicossocial - Álcool, Crack e outras drogas (CAPS-ad) de Itajaí-SC, atende usuários diariamente que fazem uso prejudicial de substâncias psicoativas. Atualmente sua equipe técnica é composta por 11 profissionais sendo 1 médico, 1 enfermeira, 2 técnicos em enfermagem, 2 terapeutas ocupacionais, 4 psicólogas e 1 psiquiatra. Utiliza o Projeto Terapêutico Singular (PTS) ${ }^{1}$ como instrumento de trabalho para o tratamento desses indivíduos e tem a Redução de Danos como estratégia norteadora à sua prática de atendimento. Suas instalações não possuem um local adequado para a realização de práticas corporais, sendo normalmente utilizados um pátio, uma sala improvisada ou um espaço sob uma marquise, dependendo da atividade proposta.

Definir com precisão o significado e a abrangência do termo "práticas corporais" ainda é um desafio na comunidade científica, e não seria diferente para a equipe técnica aqui investigada. De acordo com Lazzarotti Filho et al (2010) a Educação Física é o campo de conhecimento que mais utiliza o termo "práticas corporais" em artigos, teses e dissertações. Enfatizam que o termo ainda se encontra em fase de consolidação e necessita ser mais bem elaborado para que haja uma adequada comunicação entre a comunidade acadêmica e a sociedade. De modo correlato ao apresentado por Lazzarotti Filho et al (2010) sobre a indefinição do termo "práticas corporais" na comunidade acadêmica, a amplitude e dispersão conceitual deste termo pôde ser observada nas respostas de alguns entrevistados, quando questionados sobre o que entendem por este termo e como se faz presente no cotidiano das atividades propostas: “[...] eles pedem bastante por atividades [...] no geral eles pedem a atividade física [...]” (entrevistado 1); “[...] eles gostam bastante de oficinas relacionadas as práticas corporais [...]” (entrevistado 2); “[...] algo que traga um divertimento sem uma pressão, uma brincadeira [...]” (entrevistado 3); "[...] mais a questão envolvida com lazer, assim como a recreação [...]. ” (entrevistado 4); “[...] as que são relacionadas ao esporte [...]". (entrevistado 8).

Sem evidenciar de forma cabal o conhecimento sobre quais atividades englobam o universo das práticas corporais, esses relatos expressam que para a equipe técnica o termo "práticas corporais" está mais relacionado às práticas esportivas e ao exercício físico, com exceção de uma entrevista que citou atividades relacionadas à natureza e práticas expressivas:

“[...] no meu entendimento o que mais se aproxima de práticas corporais seria atividade do teatro [...] e a oficina de horta que é o que eu entendo que se aproxima mais das práticas corporais [...]" (entrevistado 9); e outras duas entrevistas que correlacionaram as práticas corporais com atividades introspectivas, indicando-as como "técnicas de relaxamento" (entrevistado 11) e "relaxamento" (entrevistado 10).

Entre as práticas esportivas citadas pela equipe técnica, as que envolvem jogos coletivos com bolas são as que possuem, segundo opinião dos profissionais entrevistados, a maior preferência por parte dos dependentes

\footnotetext{
${ }^{1}$ O Projeto Terapêutico Singular (PTS) "é um conjunto de propostas de condutas terapêuticas articuladas, para um sujeito individual ou coletivo, resultado da discussão coletiva de uma equipe interdisciplinar, com apoio matricial se necessário. Geralmente é dedicado a situações mais complexas". Busca-se de maneira coletiva discutir e construir alternativas terapêuticas para casos clínicos individuais ou grupais. (BRASIL, 2007, p. 40)
} 
químicos e, consequentemente, maior adesão à atividade: “[...] a quem tem mais adesão mesmo é quando envolve a bola [...]" (entrevistado 2); “[...] percebo que as práticas que envolvem esportes coletivos, são as que eles mais aderem [...]" (entrevistado 5); “[...] Atividades com bola e atividades que compõe equipes [...]” (entrevistado 7).

É compreensível de se entender quais motivos levam os dependentes químicos a preferirem esse tipo de prática corporal, pois o jogo é uma atividade livre e desobrigada de regras sociais, também regido pelas incertezas e imprevisibilidades de resultados, proporcionando divertimento e alegria, contrapondo-se a seriedade atribuída as coisas objetivas e produtivas transformando-se, assim, no alicerce do divertimento, da criação, do prazer e da plena expressão corporal e da vontade (LOPES; MADUREIRA, 2006).

Segundo Gonzaléz (2015) as práticas corporais estão vinculadas à saúde desde a antiguidade, sendo que o exercício físico sempre foi incluído e indicado para o cuidado ampliado da saúde. Barbanti (2012) relata que o tratamento da dependência química normalmente é multidisciplinar, individualizado e complexo, e que além da conduta médica, a realização de exercícios físicos (entendido como práticas corporais) mesmo sem embasamento científico sempre teve como objetivo a eliminação de toxinas, socialização, estímulo para o lazer através de caminhadas e jogos, resgate da autoestima e melhorias físicas e cardiocirculatórias. Neste contexto, quando a equipe técnica aqui investigada relata os objetivos dos dependentes químicos quanto às práticas corporais, podemos observar múltiplos olhares: um voltado à parte social, tal como apontado pela seguinte fala: "[...] não necessariamente aquela de condicionamento físico, mas uma que favoreça a interação deles, a socialização" (entrevistado 4); e outro voltado ao físico: "[...] eles tem mais interesse na questão que visa conhecer o corpo [...]" (entrevistado 10); e ainda "[...] busca de saúde e melhor condicionamento físico" (entrevistado 11). Há também aquelas falas voltadas a fatores psicológicos "[...] ouvi de alguns deles que ficavam mais motivados porque era o momento que eles se distraiam, riam bastante era como se fosse um regresso pra infância [...]” (entrevistado 10).

Sabe-se que as práticas corporais estão relacionadas a várias mudanças físicas, psicológicas e sociais. Barbanti (2006) afirma haver farta evidência sobre a associação da atividade física, exercícios físicos e esportes na melhoria da saúde mental e qualidade de vida, mesmo que esse seja um termo de difícil definição, pois depende de uma complexa combinação de fatores como saúde física, bem-estar psicológico, satisfação social e conforto espiritual.

Já o componente psicológico é citado quando relacionado a diversos aspectos, como por exemplo, à autoestima: "[...] essa atividade física melhorou a autoestima [...]” (entrevistado 1); "[...] acredito que com isso veio trazer uma autoestima [...]" (entrevistado 10), ou ainda, à ansiedade: "muda a questão da ansiedade, eles diminuem bastante, desaceleram [...]" (entrevistado 2); "a questão relacionada a 'fissura' diminui [...]" (entrevistado 4), ou à mudança comportamental: “[...] restabelece algumas questões de limites [...]” (entrevistado 4); “[...] deixa eles, dependendo da atividade, mais calmos ou as vezes até mais eufóricos [...]” (entrevistado 8), e por fim, às questões emocionais: “[...] consegue trabalhar várias questões psicológicas emocionais [...]” (entrevistado 4). 
Quanto à questão social obtivemos relatos que indicam uma alteração na socialização: “[...] ajudou muito na relação interpessoal entre eles e com a equipe [...]" (entrevistado 3); "[...] percebo que eles interagem melhor principalmente entre eles mesmos [...]" (entrevistado 5); "os usuários eles ficam mais empáticos uns com os outros, eles começam a criar afinidades e até a se ajudar mutuamente [...]” (entrevistado 7); “[...] é um momento assim que eles conseguem se abrir mais, interagirem mais com outros usuários" (entrevistado 9). Também foi citado, no quesito relacionado às questões sociais, a reinserção social: “[...] estimulou a prática fora também, estimulou para que as pessoas fossem mais para a comunidade, sociedade para fazer os esportes [...]” (entrevistado 3); “[...] alguns eu soube que foram buscar em outros espaços essas atividades, isso gera uma mudança de comportamento tanto no sentindo da inserção no social, de ressocializar, buscar novas práticas de vida [...]”" (entrevistado 6).

Independente do maior ou menor grau de importância nas mudanças físicas, psicologias ou sociais, sabe-se que todas estão relacionadas à saúde e qualidade de vida, conforme conclui Costa et al (2003) em seus estudos quando relata que os aspectos físicos, psicológicos e sociais são partes integrantes do conceito de saúde e nas diferentes razões que motivam os indivíduos à prática de atividades físicas, sendo que esses aspectos alternam-se em grau de prioridade dependendo do grupo que está sendo avaliado, e afirma que o prazer promovido pela prática é o principal motivador do indivíduo a sua participação.

O Projeto Terapêutico Singular (PTS) é um instrumento de trabalho que possibilita a participação do usuário auxiliando a construção de sua autonomia. Esse instrumento considera o contexto em que o indivíduo está inserido, suas necessidades individuais e sua historicidade. A elaboração desse projeto é feita pelo usuário, pela família e pelo profissional-referência em conjunto com a equipe técnica por meio de discussões e estudo de caso (BRASIL, 2007). As práticas corporais possuem um rol de atividades que podem ser ofertadas como opções para a construção dos PTS. É uma estratégia interessante para adesão dos dependentes químicos, visto que há solicitação, por parte deles, quando da elaboração dos seus PTS, conforme pode ser observado nos seguintes depoimentos dos entrevistados: "No geral eles pedem a atividade física, eles gostam que dentro do projeto terapêtico do CAPs tenha uma atividade física inserida, quando não tem eles sentem falta" (entrevistado 1); "[...] eu percebo é que faz falta ter no projeto, alguns questionam assim "ah não tem nenhum esporte ou alguma coisa que a gente possa se movimentar" (entrevistado 3); "[...] uma unidade de saúde deve ter atividade física, prática corporal, eles gostam" (entrevistado 4); “[...] mas percebe-se que eles de certa forma se interessam por isso e que faz falta [...]"(entrevistado 5).

Para Weinberg e Gould (2001) os motivos de adesão estão relacionados à satisfação, pois a diversão é primordial para a execução das atividades, a construção da autoestima, a realização do inimaginável e o reconhecimento externo a suas novas habilidades, assim como, para a socialização que combate a solidão e proporciona a aquisição de novas amizades e apoio social mútuo. Assim, relatos da equipe relacionam às práticas corporais a adesão aos projetos terapêuticos singulares: "[...] foi a atividade física que fez ele vincular ao seu projeto terapêutico e eu acho que isso foi muito positivo [...]” (entrevistado 1); “[...] quando tem pra ofertar a gente percebe que tem um grande aumento de usuários [...]” (entrevistado 2); “[...] Sim, com certeza, além de ser uma 
atividade que eles não esperam ser corriqueiras [...]” (entrevistado 3); “[...] Sim porque essas atividades quando fazem parte do quadro do projeto terapêutico eles querem realmente estar participando [...]" (entrevistado 7).

O CAPS-ad já teve um programa de práticas corporais que ofertava as práticas esportivas através de jogos coletivos com bolas como o futebol, vôlei e outros jogos; práticas corporais introspectivas como alongamentos e relaxamento; exercícios físicos como circuitos de ginástica e lutas com aulas de boxe. Atualmente possuem práticas corporais expressivas com aulas de teatro e práticas corporais na natureza com uma horta. Sobre a relação das práticas corporais à adesão, sua importância foi quase uma unanimidade para a equipe técnica, exceção feita a um membro que apesar de não vincular as práticas corporais à adesão, afirmou que a mesma faz muita falta quando não é ofertada nos programas terapêuticos. "[...] faz falta ter no projeto, não que contribui para uma maior adesão [...]" (entrevistado 3).

Em relação à participação familiar, no acompanhamento ao tratamento do dependente químico, a equipe afirma que esta participação é quase inexistente, conforme podemos observar na seguinte fala: “[...] a gente aqui tem muito pouca participação da família [...]" (entrevistado 6), fato ocasionado, segundo eles, por não possuírem a consciência de que sua participação é um fator importante no tratamento dos dependentes químicos, constatado pela seguinte fala: "[...] os familiares não conseguem perceber que a gente precisa deles para poder proporcionar um tratamento eficaz"(entrevistado 2). Tuller et al (2009) afirmam que é comum na história dos dependentes químicos dados que indiquem a falta de estrutura familiar com ambientes marcados pela instabilidade, incompreensão, falta de afeto, rejeição, malevolência e indiferença.

Em relação ao relacionamento familiar dos dependentes químicos, a equipe técnica em sua maioria não observou se as práticas corporais proporcionaram alguma mudança, conforme observamos nas seguintes falas: “[...] ainda não deu pra perceber não que estreitou os laços dos familiares com os dependentes[...]" (entrevistado 2); “[...] não percebo que essa prática tenha contribuído[...]”(entrevistado 6), ressalva um dos entrevistados, que possui uma opinião divergente da equipe em relação ao tema, quando relata que no seu ponto de vista acredita que as práticas corporais modificam o relacionamento familiar, fato este observado na seguinte fala: “[...] "Sim principalmente se a gente faz atividades que envolvem familiares, pois os mesmos querem que esses participem [...]" (entrevistado 7). Este registro demonstra o entendimento que o entrevistado tem sobre um dos desejos dos dependentes químicos sobre a participação familiar no seu convívio e tratamento. Essa consciência corrobora com o que Tuller et al. (2009) dizem em seus estudos quando afirmam que é unânime entre os dependentes químicos, quando questionados sobre as perspectivas do futuro, o desejo de ter dias melhores com a construção ou restauração da família, conseguir ou se manter no trabalho e estudar.

A International Harm Reduction Association (IHRA, 2010) define a Redução de Danos como "um conjunto de políticas e práticas cujo objetivo é reduzir os danos associados ao uso de drogas psicoativas em pessoas que não podem ou não querem parar de usar drogas", e entende que:

a redução de danos complementa outras medidas que visam diminuir o consumo de drogas como um todo [...] que a maioria das pessoas que usam drogas não precisam de tratamento [...] há uma 
necessidade de prover pessoas que usam drogas com opções que minimizem os riscos de continuarem usando drogas e acabem causando danos a eles próprios ou a outros [...] é essencial a existência de informações, serviços e outras intervenções de redução de danos que ajudem as pessoas a se manter seguros e saudáveis [...] muitas pessoas que usam drogas preferem utilizar maneiras informais e "não clínicas" para diminuir seu consumo de drogas ou pelo menos diminuir os riscos associados ao consumo [...] (IHRA, 2010).

Por conseguinte, podemos compreender e considerar, ponderando as entrevistas com o entendimento que expomos acima sobre o que é a Redução de Danos, que para essa equipe técnica, as práticas corporais em seus mais diversos braços de atuação podem contribuir de forma contundente na estratégia de Redução de Danos.

\section{Conclusões}

Os relatos aqui investigados evidenciam que a equipe técnica possui conhecimento ou já vivenciou as práticas corporais em algum momento de suas vidas. Apesar dos investigados afirmarem não terem ciência de todo o universo que engloba esta atividade, de uma forma geral, acreditam que esta deveria integrar o rol de opções que são disponibilizadas aos dependentes químicos quando da construção de seu PTS.

Alegam que, independente do grau de importância, as práticas corporais proporcionam mudanças físicas, psicológicas e sociais que podem auxiliar no tratamento e reinserção social. Dentre as práticas corporais citadas, acreditam que as que envolvem jogos coletivos com bola são as que despertam maior interesse. É quase unânime ao afirmarem que as práticas corporais promovem uma maior adesão aos PTS. Fazem menção a não participação familiar junto ao dependente químico, e são categóricos ao afirmar a importância dos familiares durante este processo. De uma forma geral reconhecem que devido a não participação familiar não possuem informações sobre possíveis mudanças no relacionamento familiar.

Quando advertem sobre a importância das práticas corporais, como instrumento auxiliar no tratamento, e dos questionamentos que os usuários fazem sobre sua disponibilidade, percebemos como se faz necessária a contratação de um profissional de Educação Física. Exaltamos que outras pesquisas também evidenciam a importância das práticas corporais, em várias categorias, para a melhoria da saúde e qualidade de vida, não só dos dependentes químicos, mas de toda população independente de gênero, idade, patologia ou aptidão física, no entanto, são necessários maiores investimentos, públicos ou privados, em projetos e programas que utilizem as práticas corporais na área da saúde, em especial, na saúde mental, bem como a contratação de profissionais especializados que atendam a esta demanda.

Acreditamos, assim, que independente da ótica e do campo, seja da Saúde Pública ou da Saúde Coletiva, as práticas corporais deveriam ser incorporadas como atividades indispensáveis em qualquer espaço de saúde.

\section{Referências}


ARAÚJO, M. A. P.; MOREIRA, F. G. Aspectos Históricos da Redução de Danos. PROAD - Programa de Orientação e Atendimento a Dependentes. Drogas e Redução de Danos: uma cartilha para profissionais de saúde. [S. 1.: s. n.], 2008.

BARBANTI, E. J. Efeitos da Atividade Física na Qualidade de Vida em Pacientes com Depressão e Dependência Química. In Revista Brasileira de Atividade física \& Saúde, Florianópolis, v.11, n.1, p.37-45, 2006.

BARBANTI, E. J. A importância do exercício físico no tratamento da dependência química. In Educação Física em Revista. Brasília, v.6, n.1, 2012.

BARDIN, L. Análise de conteúdo. Lisboa: Edições 70, 1979.

BRASIL. Ministério da Saúde. Conselho Nacional de Saúde. Relatório Final da III Conferência Nacional de Saúde Mental. Brasília: Ministério da Saúde, 2001. Disponível em:http://conselho.saude.gov.br/biblioteca/relatorios/saude_mental.pdf. Acesso em: 03 Mar. 2016.

BRASIL. Ministério da Saúde. Portaria GM n 336, de 19 de fevereiro de 2002. Brasília: Diário oficial da União. Disponível em: http://portal.saude.gov.br/portal/arquivos/pdf/Portaria\%20GM\%20336-2002.pdf. Acesso em: 03 Mar. 2016.

BRASIL. Ministério da Saúde. Secretaria de Atenção à Saúde. Departamento de Ações Programáticas Estratégicas. Saúde mental no SUS: os centros de atenção psicossocial. Brasília: Ministério da Saúde, 2004.

BRASIL. Ministério da Saúde. Secretaria de Atenção à Saúde. Núcleo Técnico da Política Nacional de Humanização. Clínica ampliada, equipe de referência e projeto terapêutico singular / Ministério da Saúde, Secretaria de Atenção à Saúde, Núcleo Técnico da Política Nacional de Humanização. 2. ed. Brasília: Ministério da Saúde, 2007.

BRASIL. Ministério da Saúde. Secretaria de Atenção à saúde. DAPES/SAS/MS. Coordenação Geral da Saúde Mental, Álcool e Outras Drogas. Saúde Mental no SUS: as novas fronteiras da Reforma Psiquiátrica. Relatório Gestão 2007-2010. Brasília: Ministério da Saúde, 2011.

COSTA, I. T. et al. A importância da atividade física para a manutenção da saúde e os principais fatores que motivam professores, alunos e funcionários de duas universidades brasileiras a praticarem exercício. Revista Brasileira de Educação física e saúde. v.8, n.1, p. 52-61, 2003.

FRAGA, A. B.; CARVALHO, Y. M.; GOMES, I. M. (orgs.). As práticas corporais no campo da saúde. São Paulo, Hucitec, 2013.

GIL, A. C. Como elaborar projetos de pesquisa. 5. ed. São Paulo: Atlas, 2010.

GOMES, I. M.; FRAGA, A. B.; CARVALHO, Y. M. (orgs.). Práticas corporais no campo da saúde: uma política em formação. Porto Alegre: Rede UNIDA, 2015. Disponível em:

https://www.google.com.br/?gwsrd=ssl\#q=Pr\%C3\%A1ticas+corporais+no+campo+da+sa\%C3\%BAde. Acesso em: 06 jul. 2017.

GONZALÉZ, F. J. Práticas Corporais e o sistema único de saúde: desafios para intervenção profissional. In: GOMES, I. M.; FRAGA, A. B.; CARVAlho, Y. M. (orgs.) Práticas Corporais no Campo da Saúde: uma política em formação. 1 ed. Porto Alegre: Rede Unida, p.135-162, 2015.

INTERNATIONAL HARM REDUCTION ASSOCIATION. O que é redução de danos? Uma posição oficial da Associação Internacional de Redução de Danos. Londres: [s. n.], 2010. 
LAZZAROTTI FILHO, A. et al. O termo práticas corporais na literatura científica brasileira e sua repercussão no campo da Educação Física. Movimento, Porto Alegre, v. 16, n. 01, jan/mar, p.11-19, 2010.

LOPES, J.; MADUREIRA, J. R. A educação física em jogo: práticas corporais, expressão e arte. In: Revista Brasileira de Ciências do Esporte, v.27, n.2, p.9-25, jan. 2006.

MANSKE, G. BARCELOS, T. S. Práticas corporais medicalizantes: diagnosticando a revista vida simples. In: Movimento. Porto Alegre, v. 22, n. 1, p. 233-246, jan./mar. 2016.

MIALICK, E. S. et al. A Importância da Prática de Atividade Física como Auxílio no Processo de Tratamento para a Dependência Química em Pessoas de 18 a 35 anos. São Paulo, 2010. Disponível em: http://www.cdof.com.br/A\%20import\%E2ncia\%20da\%20pr\%E1tica\%20de\%20atividade\%20f\%EDsica\%20como $\% 20$ aux $\%$ EDlio $\% 20$ no $\% 20$ processo $\% 20$ de $\% 20$ tratamento $\% 20$ para $\% 20 \mathrm{a} \% 20$ depend $\%$ EAncia $\% 20$ qu $\%$ EDmica $\% 2$ 0em\%20pessoas\%20de\%2018\%20a\%2035\%20anos.pdf Acesso em: 10 jun. 2017.

ORGANIZAÇÃO MUNDIAL DE SAÚDE. Integração da saúde mental nos cuidados de saúde primários: uma perspectiva $\quad$ global, $2008 . \quad$ Disponível em: http://www.who.int/eportuguese/publications/Integracao_saude_mental_cuidados_primarios.pdf?ua=1 Acesso em: 06 jul. 2017.

PASSOS, E. H.; SOUZA, T. P. Redução de Danos e Saúde Pública: Construções alternativas à política global de “Guerra às Drogas". Psicologia \& Sociedade, v.23, n.1, p.154-162, 2011.

PIMENTEL, G. G. A. et al. Significados das práticas corporais no tratamento da dependência química. Interface Comunicação, Saúde e Educação, Botucatu/SP, v. 12, n. 24, p. 61-71, 2008.

POLLO-ARAUJO, M. A.; MOREIRA, F. G. Aspectos Históricos da Redução de Danos. In NIEL, M.; SILVEIRA, D. X. (org). Drogas e Redução de Danos: uma cartilha para profissionais de saúde. São Paulo: UNIFESP, 2008. p. 11-20.

RIZZINI, I. et al. Pesquisando: guia de metodologias de pesquisa para programas sociais. Rio de Janeiro: USU Editora Universitária, 1999.

TULLER, N. G. P. et al. Os sofrimentos e danos biopsicossociais de dependentes químicos em recuperação. Revista Cesumar - Ciências Humanas e Sociais Aplicadas. V.14, n.1, p.137-174, 2009.

WACHS, F.; ALMEIDA, U. R.; BRANDÃO, F. F. F. (org.) Educação física e saúde coletiva: cenários, experiências e artefatos culturais, Porto Alegre: Rede UNIDA, 2016.

WEINBERG, R. S; GOULD, D. Fundamentos da psicologia do esporte e do exercício. Porto Alegre: Artmed, 2001 .

\section{Como citar este artigo}

MANSKE, George Saliba; ONISHI, Luiz Antonio. Percepção da equipe técnica sobre as práticas corporais na redução de danos em dependentes químicos. Revista Kinesis, Santa Maria, v. 37, p. 01-11, 2019. 